\title{
The Relation between Histopathologic Findings on Surgical Specimen and Outcomes in Patients with N2 Positive Stage IIIA Non-Small Cell Lung Cancer Receiving Preoperative Concurrent Radiochemotherapy and Surgery
}

\author{
BoKyong Kim, M.D. ${ }^{1}$, Kyoung Ju Kim, M.D. ${ }^{1}$, Yong Chan Ahn, M.D. ${ }^{1}$, Do Hoon Lim, M.D. ${ }^{1}$, Won Park, \\ M.D. ${ }^{1}$, Joungho Han, M.D. ${ }^{2}$, Keunchil Park, M.D. ${ }^{3}$, Kwan Min Kim, M.D. ${ }^{4}$, Jhingook Kim, M.D. ${ }^{4}$ and Young \\ Mog Shim, M.D. ${ }^{4}$ \\ Departments of ${ }^{1}$ Radiation Oncology, ${ }^{2}$ Pathology, ${ }^{3}$ Internal Medicine and ${ }^{4}$ Thoracic Surgery, Samsung Medical Center, \\ Sungkyunkwan University School of Medicine, Seoul, Korea
}

Purpose: To evaluate the prognostic implication of histopathologic findings on the surgical specimens of $\mathrm{N} 2$ positive stage IIIA non-small cell lung cancer (NSCLC) patients who were treated with preoperative concurrent radiochemotherapy (CRCT) and surgery.

Materials and Methods: From May 1997 to April 2000, 48 patients with $\mathrm{N} 2$ positive stage IIIA NSCLC were treated with preoperative CRCT and surgery. Retrospective analyses were performed on 33 patients who underwent surgical resection. The thoracic radiation therapy (TRT) dose was $45 \mathrm{~Gy}$ over 5 weeks with a $1.8 \mathrm{~Gy}$ daily fraction using $10 \mathrm{MV} X$-rays. Chemotherapy consisted of two cycles of intravenous cisplatin $\left(100 \mathrm{mg} / \mathrm{m}^{2}\right.$, on days 1 and 29$)$ and oral etoposide $\left(50 \mathrm{mg} / \mathrm{m}^{2} /\right.$ day, on days 1 14 and $29 \sim 42$ ), concurrently delivered with TRT. Surgery was performed around 4 weeks of the completion of CRCT. The median follow up was 18 months. The histopathologic findings, including the proportions of viable tumor cells, fibrosis, and necrosis, as well as the tumor and nodal statuses on the surgical specimens following the preoperative CRCT, were analyzed.

Results: The 3-year overall survival, disease-free survival, and local control rates were $46.1 \%, 49.5 \%$, and $85.5 \%$, respectively. Post-surgical stages decreased in 18 patients $(54.5 \%)$, including 3 pathologic complete responses, were unchanged in $13(39.4 \%)$, and increased in two $(6.1 \%)$. On univariate analyses, the low proportion of the viable tumor cells was the only factor favorably affecting the overall survival rate $(p=0.0386)$, and the histologic type of squamous cell carcinoma was a favorable factor affecting disease free survival rate $(p=0.0452)$. On multivariate analyses, however, no factor affected the overall survival, disease free survival, or local control rates.

Conclusion: The histopathologic findings of the proportion of viable tumor cells, fibrosis, and necrosis on the surgical specimens following preoperative CRCT had few prognostic implications on uni-and multi-variate analyses. Furthermore, the primary tumor and nodal responses to preoperative CRCT did not influence the outcomes. Longer-term follow-up with a larger number of patients, however, is awaited. (Cancer Research and Treatment 2003; $35: 497-501$ )

Key Words: Non-small cell lung cancer, Radiochemotherapy, Histopathology
Correspondence: Yong Chan Ahn, Department of Radiation Oncology, Samsung Medical Center, Sungkyunkwan University School of Medicine, 50 Ilwon-dong, Gangnam-gu, Seoul 135-710, Korea. (Tel) 02-3410-2602, (Fax) 02-3410-2619, (E-mail) ycahn@ smc.samsung.co.kr

Received June 13, 2003, Accepted November 7, 2003

Current address of BoKyong Kim: Dankook University Medical Center

\footnotetext{
INTROUCTION

Treatment of N2 positive stage IIIA non-small cell lung cancer (NSCLC), although potentially resectable, has remained controversial, because of the guarded prognoses. As only a small proportion of the patients survived longer than 5 years after surgical resection, N2 positive stage IIIA disease has been traditionally thought to be inoperable or not suitable for surgery $(1 \sim 3)$. The standard treatment option for most stage IIIA NSCLC patients has been radical radiation therapy with or
} 
without chemotherapy $(4,5)$. The role of surgery in N2 disease has not been defined yet. In order to improve the local control and survival rates, preoperative concurrent radiochemotherapy (CRCT) and surgery have been widely employed and some investigators reported favorable results $(6,7)$. There are few data, however, that adequately evaluated the prognostic factors affecting the outcomes after preoperative CRCT and surgery. We retrospectively analyzed the N2 positive stage IIIA NSCLC patients who underwent preoperative CRCT and surgery at Samsung Medical Center, to evaluate the relationship between the histopathologic findings of surgical specimens following preoperative CRCT and the treatment outcomes.

\section{MATERIALS AND METHODS}

From May 1997 to April 2000, 48 patients with N2 positive stage IIIA NSCLC were enrolled in this prospective protocol of preoperative CRCT and surgery. Pretreatment evaluations included complete history taking and physical examination: peripheral blood cell counts, chemistry profiles, pulmonary function tests, chest X-rays and chest CT scan, including upper abdomen. Patients also underwent fiberoptic bronchoscopy and bone scan. In all patients, histopathologic confirmation of NSCLC was obtained by sputum cytology, bronchoscopic washing cytology and/or biopsy, or percutaneous needle aspiration cytology and/or biopsy. Mediastinal lymph node metastasis was confirmed by either mediastinoscopic biopsy or chest CT scan.

Preoperative CRCT consisted of thoracic radiation therapy (TRT) concurrent with two cycles of chemotherapy. The TRT dose was 45 Gy over 5 weeks (1.8 Gy/fraction/day, 5 fractions/ week) using $10 \mathrm{MV}$ x-rays. The TRT target volume included the primary tumor plus the ipsilateral hilar and mediastinal lymphatics with 1.5 to $2 \mathrm{~cm}$ margins in all directions. The chemotherapy regimen consisted of cisplatin and etoposide; the former was administered intravenously at $100 \mathrm{mg} / \mathrm{m}^{2}$ on days 1 and 29 , while the latter was administered orally at $50 \mathrm{mg} /$ $\mathrm{m}^{2}$ /day in two separate doses on days $1 \sim 14$ and $29 \sim 42$ of TRT. Unless the follow-up CT scan obtained within 3 weeks of preoperative CRCT showed findings of unresectability such as local or distant progression, surgery was planned at around 4 weeks of the completion of preoperative CRCT. Postoperative radiation therapy of 18 Gy in 10 fractions was recommended to the patients with risk factors of local or regional recurrence (close or positive resection margin, multiple N1 disease, N2 disease). All patients were evaluated by chest CT scan every 3 to 4 months for 2 years following surgery, and then every 4 to 6 months thereafter, for a medium follow-up of 18 months (range, 5 44 months). Other laboratory tests for identifying local or distant relapses were performed depending on subjective symptoms and signs.

Of the 48 patients enrolled in this protocol, 35 underwent surgery. Surgery was not performed because of the patient's strong refusal in seven patients, and the appearance of new distant metastatic lesion in six. We performed retrospective analyses on 33 patients, after excluding two patients who died during the postoperative convalescent period, to investigate the relationship between the histopathologic findings following
Table 1. Patient pretreatment characteristics

\begin{tabular}{|c|c|c|}
\hline Patient characteristics & Number of patients & $\%$ \\
\hline Period of follow-up & 5 44 (median: 18) months & \\
\hline Age & 39 71 (median: 60) years & \\
\hline$\leq 60$ & 17 & 51.5 \\
\hline$>60$ & 16 & 48.5 \\
\hline \multicolumn{3}{|l|}{ Sex } \\
\hline Male & 22 & 66.7 \\
\hline Female & 11 & 33.3 \\
\hline \multicolumn{3}{|c|}{ Performance status (ECOG) } \\
\hline 0 & 2 & 6.1 \\
\hline 1 & 30 & 90.9 \\
\hline 2 & 1 & 3.0 \\
\hline \multicolumn{3}{|l|}{ Histologic type } \\
\hline Adenocarcinoma & 16 & 48.5 \\
\hline Squamous cell & 15 & 45.5 \\
\hline NSCLC, NOS & 2 & 6.0 \\
\hline \multicolumn{3}{|l|}{ Initial $\mathrm{T}$ stage } \\
\hline $\mathrm{T} 1$ & 2 & 6.0 \\
\hline $\mathrm{T} 2$ & 26 & 78.8 \\
\hline $\mathrm{T} 3$ & 5 & 15.2 \\
\hline \multicolumn{3}{|l|}{ Initial tumor size $(\mathrm{cm})$} \\
\hline$\leq 3$ & 5 & 15.2 \\
\hline $3 \sim 5$ & 18 & 54.5 \\
\hline$>5$ & 10 & 30.3 \\
\hline \multicolumn{3}{|l|}{ Mediastinoscopic biopsy } \\
\hline Yes & 28 & 84.8 \\
\hline No & 5 & 15.2 \\
\hline
\end{tabular}

preoperative CRCT and the treatment outcomes. The histopathologic findings on the surgical specimens that were evaluated with respects to the prognostic significances in this study included the proportions of viable tumor cells, necrosis, and fibrosis in the primary tumors, as well as the objective response in the tumor and the node following the preoperative CRCT. The primary tumors surgically removed were entirely embedded in paraffin blocks, and the relative areas of viable tumor cells, necrosis, and fibrosis were measured and recorded by one of the co-authors $(\mathrm{JH})$ on light microscopy. These proportions of each component in the tumors and the tumor sizes were analyzed as continuous variables in uni- and multivariate analyses.

The overall survival duration was calculated from the first day of the preoperative CRCT until the date of death or the last follow-up, and the disease free survival duration was until the date of the first relapse or the last follow-up. Local relapse was defined as relapse within the TRT volume. The survival rates were calculated by the Kaplan-Meier method, and the survival rates were compared using the log-rank test. Multivariate analyses of the independent prognostic factors were performed using the Cox proportional hazards regression model. 
Table 2. Patient status after chemoradiotherapy

\begin{tabular}{lrr}
\hline Patient status & Number of patients & $\%$ \\
\hline Surgical extent & & \\
Lobectomy & 23 & 69.7 \\
Bilobectomy & 6 & 18.2 \\
Pneumonectomy & 4 & 12.1 \\
Pathologic T stage & & \\
T0 & 4 & 12.1 \\
T1 & 8 & 51.5 \\
T2 & 2 & 24.2 \\
T3 & 2 & 6.1 \\
T4 & 17 & 6.1 \\
Pathologic N stage & 2 & 51.5 \\
N0 & 14 & 6.1 \\
N1 & & 42.4 \\
N2 & 18 & 54.5 \\
Pathologic staging & 13 & 39.4 \\
Down-staged* & 2 & 6.1 \\
Unchanged & & 33.3 \\
Up-staged & 11 & 66.7 \\
Adjuvant radiotherapy & 22 & \\
Yes & & \\
No & &
\end{tabular}

*Pathological complete response was observed in 3 patients.

\section{RESULTS}

The age of the 33 patients ranged from 39 to 71 (median, 60 ) years, and the male to female ratio was $22: 11$. The ECOG performance status score was $0 \sim 1$ in 32 patients, and 2 in the other. The tumor sizes varied from 1.5 to 9.5 (median, 3.6) $\mathrm{cm}$, and the initial clinical T-stages based on the chest CT scans and the bronchoscopic findings were $\mathrm{T} 1$ in two patients (6.0\%), $\mathrm{T} 2$ in $26(78.8 \%)$, and $\mathrm{T} 3$ in five $(15.2 \%)$. Histologic types were adenocarcinoma in 16 patients $(48.5 \%)$, squamous cell carcinoma in 15 (45.4\%), and NSCLC not otherwise specified in two $(6.1 \%)$ (Table 1). Chest CT showed enlarged mediastinal lymph node(s) that were suspected of metastasi(e)s in 21 patients $(63.6 \%)$, while "N2 negative" was presumed in 11 (36.4\%). Mediastinoscopic biopsy was performed in 28 patients $(84.8 \%)$, and although it was omitted in the other five (15.2\%), the findings of central necrosis and/or extracapsular extension were evident of metastases.

Thirty-two patients underwent complete surgical resection and only one patient underwent incomplete resection because of invasion to the superior vena cava (SVC) and the pericardium by the affected lymph nodes. The surgical extents were pneumonectomy in four (12.1\%), bilobectomy in six $(18.2 \%)$ and lobectomy in 23 patients $(69.7 \%)$. Post-surgical stages decreased in 18 patients (54.5\%), including three with pathologic complete response, were unchanged in $13(39.4 \%)$, and increased in two $(6.1 \%)$. The reasons for up-staging in the latter two patients were because of the $\mathrm{T}$ factor (satellite nodule in
Table 3. Prognostic factors (Univariate analyses)

\begin{tabular}{lccc} 
Variables & $\begin{array}{c}\mathrm{OS}^{\dagger} \\
\text { (p value) }\end{array}$ & $\begin{array}{c}\text { LRFS }^{\ddagger} \\
\text { (p value) }\end{array}$ & $\begin{array}{c}\mathrm{DFS}^{\S} \\
\text { (p value) }\end{array}$ \\
\hline Pretreatment variables & & & \\
Histology & 0.0768 & 0.1526 & 0.0452 \\
T Stage & 0.2936 & 0.4625 & 0.5668 \\
Tumor size & 0.6522 & 0.0610 & 0.3349 \\
Bulky N2* & 0.4272 & 0.1498 & 0.8850 \\
Posttrevatment ariables & & & \\
Tumor size & 0.4251 & 0.6891 & 0.8427 \\
Nodal stage & 0.0809 & 0.6774 & 0.6023 \\
Down stage & 0.9567 & 0.1080 & 0.3404 \\
Viable tumor $(\%)$ & 0.0386 & 0.3018 & 0.6202 \\
Necrosis $(\%)$ & 0.9723 & 0.1479 & 0.2296 \\
\hline
\end{tabular}

The tumor size and proportions of viable tumor cells and necrosis were analyzed as continuous variables. ${ }^{*} \mathrm{~N} 2$ that was confirmed by CT scan, ${ }_{\dagger}$ overall survival, ${ }^{\ddagger}$ local relapse free survival, ${ }^{\S}$ disease free survival

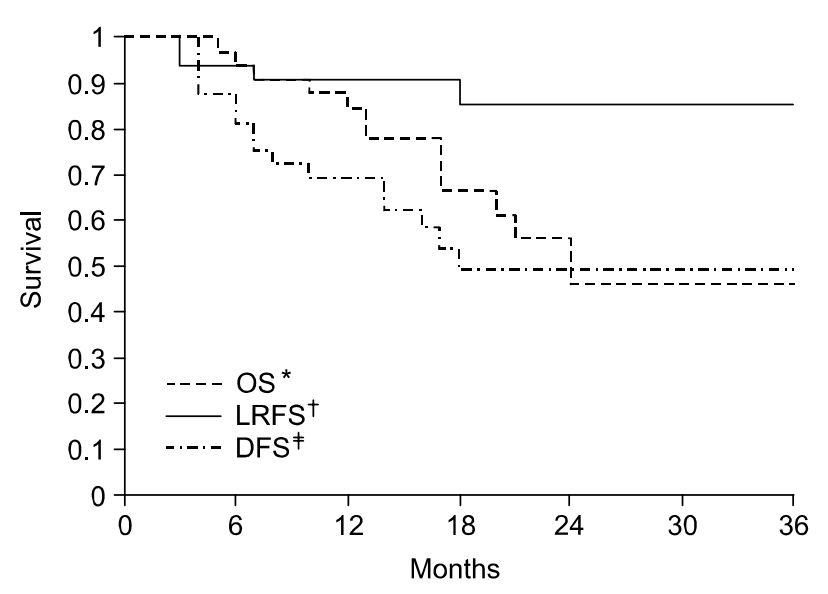

Fig. 1. Local relapse free survival, disease free survival and overall survival. ${ }^{*}$ overall survival, ${ }^{\dagger}$ local relapse free survival, ${ }^{\ddagger}$ disease free survival.

one, and invasion into the superior vena cava in the other). Pathologic complete response in the primary tumor was observed in four patients $(12.1 \%)$, and complete response in the lymph nodes in $17(51.5 \%)$ (Table 2). Eleven patients received the additional radiation therapy following surgery due to the positive N2 node(s). Three patients didn't receive adjuvant radiotherapy despite the presence of $\mathrm{N} 2$ node(s) because of patient's refusal in two cases and post-surgical empyema in the other one.

The 3-year overall survival, disease-free survival and local control rates were $46.1 \%, 49.5 \%$, and $85.5 \%$, respectively (Fig. 1). On univariate analyses of the possible prognostic factors, the only factor that showed significant influence over the overall survival rate was the proportion of viable tumor cells. The patients with a lower proportion of viable tumor cells showed 
Table 4. Prognostic factors (Multivariate analyses)

\begin{tabular}{lccc} 
Variables & $\begin{array}{c}\mathrm{OS}^{\dagger} \\
\left.\text { ( }{ }^{\dagger} \text { value }\right)\end{array}$ & $\begin{array}{c}\text { LRFS }^{\dagger} \\
(\mathrm{p} \text { value })\end{array}$ & $\begin{array}{c}\mathrm{DFS}^{\S} \\
(\mathrm{p} \text { value })\end{array}$ \\
\hline $\begin{array}{l}\text { Pretreatment variables } \\
\text { Histology }\end{array}$ & 0.1159 & 0.6714 & 0.1284 \\
T stage & 0.9151 & 0.6291 & 0.6971 \\
Tumor size & 0.0850 & 0.7872 & 0.3253 \\
Bulky N2* & 0.1592 & 0.6851 & 0.4751 \\
Posttreatment variables & & & \\
Tumor size & 0.3806 & 0.8745 & 0.1978 \\
Nodal stage & 0.6147 & 0.3837 & 0.1551 \\
Downstage & 0.1360 & 0.6950 & 0.1961 \\
Viable tumor (\%) & 0.8658 & 0.7097 & 0.8951 \\
Necrosis (\%) & 0.6536 & 0.7770 & 0.2775 \\
\hline
\end{tabular}

The tumor size and proportions of viable tumor cells and necrosis were analyzed as continuous variables. ${ }^{*} \mathrm{~N} 2$ that was confirmed by CT scan, ${ }^{\dagger}$ overall survival, ${ }^{\ddagger}$ local relapse free survival, ${ }^{\S}$ disease free survival

a better survival rate than those with a higher proportion $(\mathrm{p}=0.0386$ ). The postoperative $\mathrm{T}$ and $\mathrm{N}$ stages, however, did not influence the overall survival rate. The significant factor that favorably influenced the disease free survival rate was the histologic type of squamous cell carcinoma $(p=0.0452)$, while there was no factor that showed significant influence on the local control rate (Table 3). On multivariate analyses, there was no factor that significantly influenced any of the three rates (Table 4). Neither the histopathologic findings on the surgical specimens nor the objective response to preoperative CRCT had any prognostic implications at all.

\section{DISCUSSION}

The prognosis of stage IIIA NSCLC varies greatly depending on the extent of mediastinal lymph node metastasis. Following surgery, the 5-year survival rate of $\mathrm{N} 2$ disease at the microscopic level usually was in the $20 \sim 33 \%$ range $(8,9)$, while that of mediastinoscopic or clinical (on CT scan) N2 disease was in the $9 \sim 18 \%$ range $(10,11)$.

In order to improve the treatment results in N2 positive stage IIIA NSCLC, several efforts have been tried, including preoperative chemotherapy with or without CRCT. The preoperative chemotherapy trials theoretically aimed to reduce the local tumor bulk, thereby increasing the respectability, and to eliminate the probable distant micrometastases that had been the most common treatment failure following surgical resection (12 14). A few studies, in fact, have already suggested that preoperative chemotherapy and surgery improve both the resectability and survival in stage III NSCLC $(15 \sim 17)$.

Weitberg, et al. conducted a trial using induction radiation therapy plus two cycles of concurrent chemotherapy with cisplatin and etoposide that were followed by surgery and adjuvant chemotherapy (6). After induction radiochemotherapy, the clinical response rate was $89 \%$, and the complete resection rate was $81 \%$ at $4 \sim 6$ weeks of postinduction. The median survival duration of those after resection was 24 months, and the 2-year survival rate was approximately $50 \%$. The Southwest Oncology Group (SWOG) carried out a phase II trial of two cycles of cisplatin and etoposide plus concurrent chest radiation therapy up to 45 Gy that were followed by surgery (7). The resectability rate was $85 \%$ for the IIIA (N2) group, and the 3 -year survival rate was $27 \%$. The strongest predictor of long-term survival after surgery was the absence of tumor in the mediastinal node at the time of surgery $(p=0.0005)$. In our study, 32 out of 33 patients in whom thoracotomy was attempted underwent complete surgical resection and the post-surgical stages were lowered in 27 patients $(81.8 \%)$, including three pathologic complete responses. Based on the current observations, the TRT dose of 45 Gy concurrent with EP chemotherapy is judged to be reasonably effective in improving the resectability and survival rates. The 3-year overall survival, disease free survival and local control rates, of $46.1 \%, 49.5 \%$, and $85.5 \%$ in this study, compare favorably with those in other studies using preoperative CRCT and surgery, and are better than those using definitive CRCT alone.

A few studies have investigated the factors to predict the long-term survival after preoperative CRCT and surgery. Bueno et al. reviewed the patients who underwent induction therapy followed by resection for N2 positive stage IIIA NSCLC (18). Preoperative therapy consisted of cisplatin-based chemotherapy, radiotherapy, or chemoradiotherapy. The overall 5-year survival rate was $17.5 \%$ with a median survival duration of 17.8 months. The significant prognostic factor was the nodal stage after induction therapy: the 5-year survival rate among the patients with pN0 disease was $35.8 \%$, while that among pN1 and pN2 disease patients, at $9 \%$, was significantly worse $(p=0.023)$. Other prognostic factors that adversely affected the survival rate were adenocarcinoma histology and pneumonectomy. Milano et al. proposed the four-grade system in histopathological evaluation, and compared this system with the clinical outcomes in 20 patients with stage III NSCLC who received induction chemotherapy and surgery (19). Their histological grading system was based on the presence and extent of verified necrosis. They suggested that their histopathological grading system could be an objective parameter of the chemotherapy effectiveness. Andre et al. evaluated the outcome of 63 patients with stage IIIB NSCLC treated with 3 cycles of chemotherapy (cisplatin, vindesine, lomustine, and cyclophosphamide) followed by TRT ( 65 Gy) (20). They reported that the persistence of viable tumor cells in the bronchoscopic biopsy specimen following definitive CRCT is an early indicator of treatment failure and death, even when favorable clinical tumor response had been achieved.

We analyzed the relationship between survival rates and both histopathologic findings and tumor response to preoperative CRCT. We analyzed the proportion of viable tumor cells, necrosis, and fibrosis in the primary tumors as continuous variables instead of proposing a new grading system. As findings of necrosis and fibrosis are also present in untreated intact tumors, we assumed that their proportions after the induction treatment, without knowing the initial proportions, had less prognostic implications than would have been expected. Also we wanted to avoid any oversimplification and artificiality 
inherent in the use of a grading system. It was found, on univariate analyses, that the lower the proportion of viable tumor cells, the better the overall survival rate $(\mathrm{p}=0.0386)$. On multivariate analyses, however, there was no factor that significantly affected the overall survival, disease free survival, or local control rates. Based on the current observations, we suggest that the histopathologic findings on the surgical specimens, as well as the tumor response to preoperative CRCT, have few prognostic implications. The fact that the significance of the viable tumor cell proportion proven on univariate analysis was offset on multivariate analysis may be explained either by the rather small sample size or the small number of follow-up observations. Longer-term follow-up of a larger number of patients is therefore necessary.

\section{CONCLUSIONS}

The histopathologic findings of the proportion of viable tumor cells, fibrosis, and necrosis on the surgical specimens following preoperative CRCT had few prognostic implications on uni- and multi-variate analyses. Furthermore, the primary tumor and nodal responses to preoperative CRCT did not influence the overall survival, disease free survival, or local control rates. However a longer-term follow-up with a larger number of patients is necessary for confirmation of these findings.

\section{REFERENCES}

1. Martini N, Flehinger BJ, Zaman MB, Beattie EJ Jr. Results of resection in non-oat cell carcinoma of the lung with mediastinal lymph node metastases. Ann of Surg 1983;198: 386-397.

2. Martini N, Flehinger BJ. The role of surgery in N2 lung cancer. Surg Clin North Am 1987;67:1037-1049.

3. Shields TW. The significance of ipsilateral mediastinal lymph node metastasis (N2 disease) in non-small cell carcinoma of the lung. J Thorac Cardiovasc Surg 1990;99:48-53.

4. Shin KH, Park CI, Shim YS, Bang YJ, Han SK. Concomitant boost radiotherapy for stage III non-small cell lung cancer. J Korean Cancer Assoc 1998;30:1110-1118.

5. Sause W, Kolesar P, Taylor S IV, Johnson D, Livingston R, Komaki R, Emami B, Curran W Jr, Byhardt R, Dar AR, Turrisi A 3rd. Final results of phase III trial in regionally advanced unresectable non-small cell lung cancer: Radiation Therapy Oncology Group, Eastern Cooperative Oncology Group, and Southwest Oncology Group. Chest 2000;17:358364.

6. Weitberg AB, Yashar J, Glicksman AS, Posner M, Cummings F, Browne M, Clark J, Calabresi P, Beitz J, Murray C. Combined modality therapy for stage IIIA non-small cell lung carcinoma of the lung. Eur J Cancer 1993;29A:511-515.

7. Albain KS, Rusch VW, Crowley JJ, Rice TW, Turrisi AT 3rd, Weick JK, Lonchyna VA, Presant CA, McKenna RJ, Gandara
DR. Concurrent cisplatin/etoposide plus chest radiotherapy followed by surgery for stage IIIA (N2) and IIIB non-small cell lung cancer: mature results of Southwest Oncology Group Phase II study 8805. J Clin Oncol 1995;13:1880-1892.

8. Goldstraw P, Mannam GC, Kaplan DK, Michail P. Surgical management of non-small-cell lung cancer with ipsilateral node metastasis (N2 disease). J Thorac Cardiovasc Surg 1994; 107:19-28.

9. Watanabe Y, Shimizu J, Oda M, Hayashi Y, Watanabe S, Tatsuzawa Y, Iwa T, Suzuki M, Takashima T. Aggressive surgical intervention in N2 non-small-cell cancer of the lung. Ann Thorac Surg 1991;51:253-261.

10. Pearson FG, Delarue NC, Ilves R, Todd TR, Cooper JD. Significance of positive superior mediastinal nodes identified at mediastinoscopy in patients with resectable cancer of the lung. J Thorac Cardiovasc Surg 1982;83:111.

11. Coughlin M, Deslauriers J, Beaulieu M, Fournier B, Piraux M, Rouleau J, Tardif A. Role of mediastinoscopy in pretreatment staging of patients with primary lung cancer. Ann Thorac Surg 1985;40:556-560.

12. Bellamy AS. Fundamental concepts associated with combining cytotoxic drugs and x-irradiation. In: Hill BT, Bellamy AS, eds. Antitumor drug-radiation interactions. Boca Raton, FL: CRC Press, 1990:1-22.

13. Langer CJ, Curran WJ, Keller SM, Catalano R, Fowler W, Blankstein K, Litwin S, Bagchi P, Nash S, Comis R. Report of phase II trial of concurrent chemo-radiotherapy with radical thoracic irradiation (60 Gy), infusional fluorouracil, bolus cisplatin and etoposide for clinical stage IIIB and bulky IIIA non-small cell lung cancer. Int J Radiat Oncol Biol Phys 1993;26:469-478.

14. Vokes EE, Weichselbaum RR. Concomitant chemoradiotherapy: Rationale and clinical experience in patients with solid tumor. J Clin Oncol 1990;8:911-938.

15. Belani CP. Multimodality management of regionally advanced non-small cell lung cancer. Semin Oncol 1993;20:302-314.

16. Rosell R, Gomez-Codina J, Camps C, Maestre J, Padille J, Canto A, Mate JL, Li S, Roig J, Olazabal A, Canela M, Ariza A, Skacel Z, Morera-Prat J, Abad A. A randomized trial comparing preoperative chemotherapy plus surgery with surgery alone in patients with non-small cell lung cancer. $\mathrm{N}$ Engl $\mathbf{J}$ Med 1994;330:153-158.

17. Roth JA, Fosselle F, Komaki R, Ryan MB, Putnam JB Jr, Lee JS, Dhingra H, De Caro L, Chasen M, McGavran M. A randomized trial comparing perioperative chemotherapy and surgery with surgery alone in respectable stage IIIA non-small cell lung cancer. J Natl Cancer Inst 1994;86:673-680.

18. Bueno R, Richard WG, Swanson SJ, Jaklitsch MT, Lukanich JM, Mentzer SJ, Sugarbaker DJ. Nodal stage after induction therapy for stage IIIA lung cancer determines patients survival. Ann Thorac Surg 2000;70:1826-1831.

19. Milano S, Zordi F, Marini G, Zaniboni A, Ottoni DB, Di Fabio D, Mombelloni G. Histopathological grading of response to induction chemotherapy in non-small cell lung cancer: a preliminary study. Lung Cancer 1996;15:183-187.

20. Andre F, Grunewald D, Chevalier TL. Persistence of viable tumor cells after radiation and chemotherapy for stage IIIB non-small cell lung cancer: An early marker of treatment failure. J Thorac Cardiovasc Surg 2001;121:403. 